\title{
Ultrasonication Affects Crystallization Mechanisms and Kinetics of Anhydrous Milk Fat
}

\author{
Rikke P. Frydenberg, ${ }^{\dagger}$ Marianne Hammershøj, ${ }^{\dagger}$ Ulf Andersen, ${ }^{\dagger}$ and Lars Wiking* ${ }^{\dagger}$ \\ ${ }^{\dagger}$ Department of Food Science, Aarhus University, P.O. Box 50, 8830 Tjele, Denmark \\ ${ }^{\ddagger}$ Arla Strategic Innovation Centre, Arla Foods, 8200 Brabrand, Denmark
}

ABSTRACT: In this study, immediate and long-term effects of high intensity ultrasound on crystallization mechanisms of anhydrous milk fat were examined. Short time $(5 \mathrm{~s})$ ultrasound treatment $\left(24 \mathrm{kHz}, 300 \mathrm{~W} / \mathrm{cm}^{2}, 17.5 \mathrm{~J} / \mathrm{mL}\right)$ of milk fat induced crystallization onset at higher temperatures and a longer temperature interval between the crystallization of the high and low melting fractions. The solid fat content in ultrasonicated milk fat was higher during cooling to $5{ }^{\circ} \mathrm{C}$ and for the first $20 \mathrm{~min}$ of incubation at this temperature. After 20 min, the increase diminished, and during further storage, the

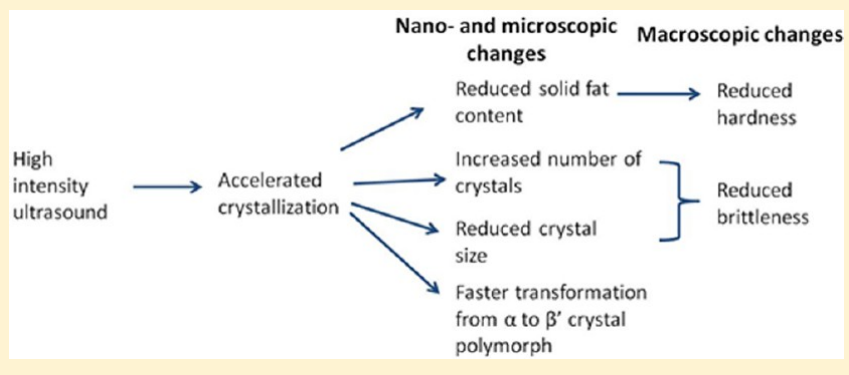
solid fat content in the ultrasonicated fat remained lower than in the nontreated fat. Ultrasound treatment promoted the formation of spherulite structures and a high degree of size uniformity. Nano- and microscopic changes lead to altered macroscopic properties, where a softer and less brittle milk fat material was obtained, and the effects were sustained during storage. These results contribute to clarify the mechanisms underlying the effects of ultrasound treatment on fat crystallization and shed light on the potential use of ultrasound in the processing chain to tailor products with desired textural properties.

\section{INTRODUCTION}

A demand for high quality foods has grown as consumers have become more aware of the quality of the food they consume. This creates a challenge for the food industry that has to develop new methods to produce high quality foods with desired textural properties. Increasing interest in the use of ultrasound to improve the processing conditions has been emerging in the food industry. High intensity ultrasound (HIU) is also denoted as "power ultrasound". It refers to sound waves with frequencies just above the range of human hearing, that is, $20-100 \mathrm{kHz}$. Depending on the intensity and frequencies applied, ultrasound can be used for nondestructive (low-intensity, high frequency) or material-altering (high intensity, low frequency) purposes. Nondestructive ultrasound is used for medical diagnostic purposes and for monitoring physicochemical properties. In the food industry it may be used to monitor crystallization and for rheological analyses. ${ }^{1} \mathrm{HIU}$ is applied in the process of defoaming, cell disruption, cleaning, emulsification, homogenization, activation and inactivation of enzymes, and induction of chemical reactions. ${ }^{2,3} \mathrm{HIU}$ has a wide application range in the food industry, and published reports include, but are not limited to, studies on meat tenderization ${ }^{4}$ and yoghurt and cheese manufacturing. ${ }^{5,6} \mathrm{HIU}$ is shown to affect crystallization, a process referred to as sonocrystallization. This is shown for several systems including sucrose, lactose, and lipid systems. ${ }^{7-10}$ Some common effects are reported across these systems, such as reduced induction time for crystallization and smaller and more uniform crystal sizes. $^{7-10}$ HIU causes cavitation, which refers to a series of compressions and rarefactions leading to the formation and implosion of vapor cavities or bubbles. ${ }^{3}$ There are two types of cavitation: noninertial, which is characterized by smallamplitude oscillations, and inertial cavitation associated with large variations in bubble size and locally very high temperatures (up to $5000 \mathrm{~K}$ ) and pressures (up to $1000 \mathrm{~atm}$ ) upon implosion. This creates a cavitation zone with high shear, mechanical pressure waves, and turbulence, and these conditions are believed to facilitate heat and mass transfer in chemical reactions. ${ }^{3,11}$ The processing conditions, such as crystallization temperature and acoustic power levels, are very important for the effects on the physical properties obtained by HIU treatment. ${ }^{8,12}$ Indeed, proportionality between nucleation and acoustic output is observed, where an increase in the latter appears to be associated with an increased number of cavitation bubbles. $^{9,12}$ In cocoa butter and pure lipid systems, HIU is shown to enable the control of the polymorphism of formed crystals by altering the conditions under which HIU is applied. ${ }^{7,13}$ Previous reports on HIU and anhydrous milk fat (AMF) have been devoted to the effects on isothermal crystallization. Suzuki et al. ${ }^{14}$ show that HIU increases the hardness of AMF as a result of an altered microstructure. Additionally, an increase in viscosity and a slight reduction in the amount of solid fat is observed. ${ }^{14,15}$

We present here our study on the effects of HIU on nonisothermal crystallization of AMF. We analyzed the effects of HIU on the crystallization mechanisms of AMF and the

Received: August 27, 2013

Revised: October 22, 2013

Published: October 23, 2013 
subsequent effects on the textural properties. To our knowledge, no studies have focused on the long-term effects of HIU, and to fully clarify the potential use of this method in the food industry these must be assessed as well. Our analyses comprise a study on HIU effects on nano- and microstructure, and macroscopic levels, which contributes to the process of clarifying the extent of HIU effects and how HIU mediates the observed effect on lipid crystallization.

\section{MATERIAL AND METHODS}

Materials. Anhydrous milk fat was used as a lipid model system. AMF was supplied by Arla Foods (Brabrand, Denmark). AMF was stored at $5{ }^{\circ} \mathrm{C}$ until use.

Sample Preparation. The AMF was heated to $65^{\circ} \mathrm{C}$ and kept at this temperature for $30 \mathrm{~min}$. This ensures complete melting of the triglycerides and deletion of crystal memory. AMF was subsequently distributed in $30 \mathrm{~mL}$ aliquots in glass tubes (PYREX no. $9826,34 \mathrm{~mL}$, $2.2 \mathrm{~cm}$ diameter), and samples were cooled $3{ }^{\circ} \mathrm{C} / \mathrm{min}$ to the temperature of HIU treatment (i.e., $14{ }^{\circ} \mathrm{C}, 22{ }^{\circ} \mathrm{C}, 26^{\circ} \mathrm{C}$, and, $30^{\circ} \mathrm{C}$ ) in a water bath. All samples were cooled $0.5^{\circ} \mathrm{C} / \mathrm{min}$ from HIU treatment temperature to $5{ }^{\circ} \mathrm{C}$.

HIU Application. HIU was applied using a U200S ultrasound processor from Hielscher (Hielscher Ultrasonics $\mathrm{GmbH}$, Germany), which has an operating frequency of $24 \mathrm{kHz}$ and maximum power output of $200 \mathrm{~W}$. HIU was applied continuously using a $7 \mathrm{~mm}$ diameter tip. Thirty milliliter samples were treated with HIU once the targeted temperature was reached. The tip of the sonotrode was placed in the middle of the sample. Preliminary studies in the laboratory performed at $28{ }^{\circ} \mathrm{C}$ indicated that HIU applied for $5 \mathrm{~s}$ (power intensity: $300 \mathrm{~W} / \mathrm{cm}^{2} ; 17.5 \mathrm{~J} / \mathrm{mL}$, amplitude: $35 \mu \mathrm{m}$ ) was sufficient to induce a change in crystallization and melting behavior. We therefore applied these settings for further experiments.

Crystallization and Melting Behavior Analysis by Differential Scanning Calorimetry (DSC). Crystallization and melting behavior was analyzed using a differential scanning calorimeter (Q1000 DSC, TA Instruments, New Castle, DE, USA). Samples of 7-15 mg of AMF were loaded in aluminum cups. An empty cup was used as a reference. Crystallization: After HIU treatment, the samples were kept at the HIU treatment temperature for 3 min before cooling to $5{ }^{\circ} \mathrm{C}$ at a cooling rate of $0.5{ }^{\circ} \mathrm{C} / \mathrm{min}$. The sample was kept isothermal at $5{ }^{\circ} \mathrm{C}$ for $5 \mathrm{~min}$ in the DSC to collect information on further crystallization. Melting: In order to evaluate the immediate and long-term effects of HIU on the melting profile of AMF, samples were analyzed immediately after cooling or after storage at $5{ }^{\circ} \mathrm{C}$ for 7 or 14 days. Samples were heated $5{ }^{\circ} \mathrm{C} / \mathrm{min}$ from 5 to $60{ }^{\circ} \mathrm{C}$ immediately after cooling or after 7 or 14 days. DSC analyses were performed in triplicates.

Solid Fat Content and Polymorphic Behavior by Low-Field Nuclear Magnetic Resonance (pNMR). Determination of solid fat content (SFC) was performed using a Maran Benchtop Pulsed NMR analyzer (Resonance Instruments, Witney, UK) operating at a frequency of $23.4 \mathrm{MHz}$. Samples were prepared and treated with HIU as described above. Immediately after HIU treatment, AMF was distributed into $10 \mathrm{~mm}$ NMR tubes and kept isothermal for $3 \mathrm{~min}$, before cooling to $5{ }^{\circ} \mathrm{C}$ with a cooling rate of $0.5{ }^{\circ} \mathrm{C} / \mathrm{min}$ in a water bath (LAUDA Ecoline, Germany). The NMR probe was an air-cooled $10 \mathrm{~mm}$ variable temperature probe (Oxford Instruments, UK) set to $15{ }^{\circ} \mathrm{C}$. The SFC was measured multiple times during the first hour of storage $(10,15,20,25,30$, and $60 \mathrm{~min})$ and after 7 and 14 days. Data are reported as averages of three measurements.

For analysis of polymorphic behavior, the procedure was as described for SFC measurements. Probe temperature was set to 5 ${ }^{\circ} \mathrm{C}$. The AMF sample was cooled to $5{ }^{\circ} \mathrm{C}$, and free-induced decay (FID) curves were collected once every minute from 0 to $40 \mathrm{~min}$ of storage. FID curves were based on eight scans and fitted using the $\mathrm{R}$ software (R Foundation for Statistical Computing, Vienna, Austria).

Solvent Fractionation. Liquid and solid fractions of AMF were separated using the method described by Marangoni et al. ${ }^{16}$ with modifications. AMF was melted and treated with HIU as described above. After HIU treatment, AMF was transferred to a glass bottle and diluted 1:4 in ethyl acetate at room temperature $\left(24 \pm 3{ }^{\circ} \mathrm{C}\right)$. Cooling and filtration were performed as described by Marangoni et al. ${ }^{16}$ In brief, the AMF and ethyl acetate mixture was transferred to a glass bottle and placed in a water bath (set at HIU treatment temperature). The mixture was cooled $0.5{ }^{\circ} \mathrm{C} / \mathrm{min}$ to $5{ }^{\circ} \mathrm{C}$ and kept at this temperature for $1 \mathrm{~h}$. The mixture was mixed by inversion every $5 \mathrm{~min}$. Solid and liquid fractions were separated by vacuum-filtration using a Buchner funnel and a Whatman No. 43 filter paper.

Triacylglyceride Analysis by Gas Chromatography. Triacylglyceride (TAG) composition was analyzed by gas chromatography (GC) on a HP6890 GC-system (Hewlett-Packard Co., Palo Alto, CA) with a flame ionization detector. Operating conditions were as follows: $2.5 \mathrm{~m} \times 0.25 \mathrm{~mm} \times 0.1 \mu \mathrm{m}$ RTX-65TG column (Restek, Bellefonte, PA, USA); inlet temperature was $250{ }^{\circ} \mathrm{C}$ with a split ratio 40:1. Helium was used as carrier gas with a constant flow of $3 \mathrm{~mL} / \mathrm{min}$. Starting temperature was set to $80^{\circ} \mathrm{C}$ for $1 \mathrm{~min}$, followed by heating to $240{ }^{\circ} \mathrm{C}$ by $30{ }^{\circ} \mathrm{C} / \mathrm{min}$ and then to $350{ }^{\circ} \mathrm{C}$ by $4{ }^{\circ} \mathrm{C} / \mathrm{min}$. Temperature was kept at $350{ }^{\circ} \mathrm{C}$ for $5 \mathrm{~min}$. Detector temperature was set to $380{ }^{\circ} \mathrm{C}$. A TAG standard mixture from Nu-Chek Prep (MN, USA) was used for reference.

Texture Analysis - Hardness and Brittleness. The hardness of the crystallized samples was measured after storage at $5{ }^{\circ} \mathrm{C}$ for 7 or 14 days by means of needle penetrometry. Analyses were carried out using a TA-Hdi texture analyzer (Stable Micro Systems Ltd., Surrey England) with a $100 \mathrm{~kg}$ load cell and $1 \mathrm{mN}$ detection range. The AMF samples were prepared as described above and transferred to plastic cubs $(\varnothing 3 \mathrm{~cm})$, resulting in a sample height of approximately $2 \mathrm{~cm}$. A standard $0.9 \mathrm{~mm}$ diameter needle probe penetrated the sample using a test speed of $0.5 \mathrm{~mm} / \mathrm{s}$ to a final depth of $7 \mathrm{~mm}$. The texture analyzer was not equipped with a cooling system; however, samples were taken from the refrigerator $\left(5{ }^{\circ} \mathrm{C}\right)$ and measured immediately. Thus sample temperature was approximately $5{ }^{\circ} \mathrm{C}$ during measurement. Five tests on each of six replicates were carried out.

To further analyze the textural changes after HIU application, tests were performed to investigate the brittleness of AMF. The procedure for evaluating brittleness was similar to the procedure described for hardness measurements with minor changes; a standard cone geometry was used for penetrating the sample using a test speed of $0.5 \mathrm{~mm} / \mathrm{s}$ to a final depth of $4 \mathrm{~mm}$. Samples were taken from the refrigerator $\left(5{ }^{\circ} \mathrm{C}\right)$ and measured immediately; thus sample temperature was approximately $5{ }^{\circ} \mathrm{C}$ during measurement. Three tests on each of four replicates were carried out.

Microstructure. The microstructure of AMF samples stored at 5 ${ }^{\circ} \mathrm{C}$ for 7 or 14 days was examined using polarized light microscopy (PLM). This method can be used to distinguish crystalline material (white) from amorphous material (black). Samples were prepared as described above and stored at $5{ }^{\circ} \mathrm{C}$ until analysis. After 7 or 14 days, small samples of AMF was transferred to glass slides. Glass slides and coverslips were cooled to $5{ }^{\circ} \mathrm{C}$ beforehand. The crystallized sample was pressed in a gentle manner against the slide using the coverslip to ensure a uniform thickness but still avoid destroying the crystal network. Images were recorded using a PLM microscope (PLM, Olympus CX 31) fitted with a digital camera. A 10× magnification was used. Samples were kept at $5{ }^{\circ} \mathrm{C}$ until immediately before analysis, which was performed at room temperature. Four representative images were taken of each of three slides prepared from each of two replicates, that is, in total 24 images per treatment and storage time.

Statistical Analysis. The results are presented as means, except for the brittleness data, where one representative data set was selected for each treatment. Significant differences between control and HIUtreated samples were determined by analysis of variance (one-way ANOVA) followed by the Tukey test using Sigmaplot software (Systat Software Inc., CA, USA, version 11.0, 2008). Differences were considered significant at $P<0.05$.

\section{RESULTS AND DISCUSSION}

Thermal Behavior of AMF. The effect of HIU on crystallization mechanisms was evaluated by differential 


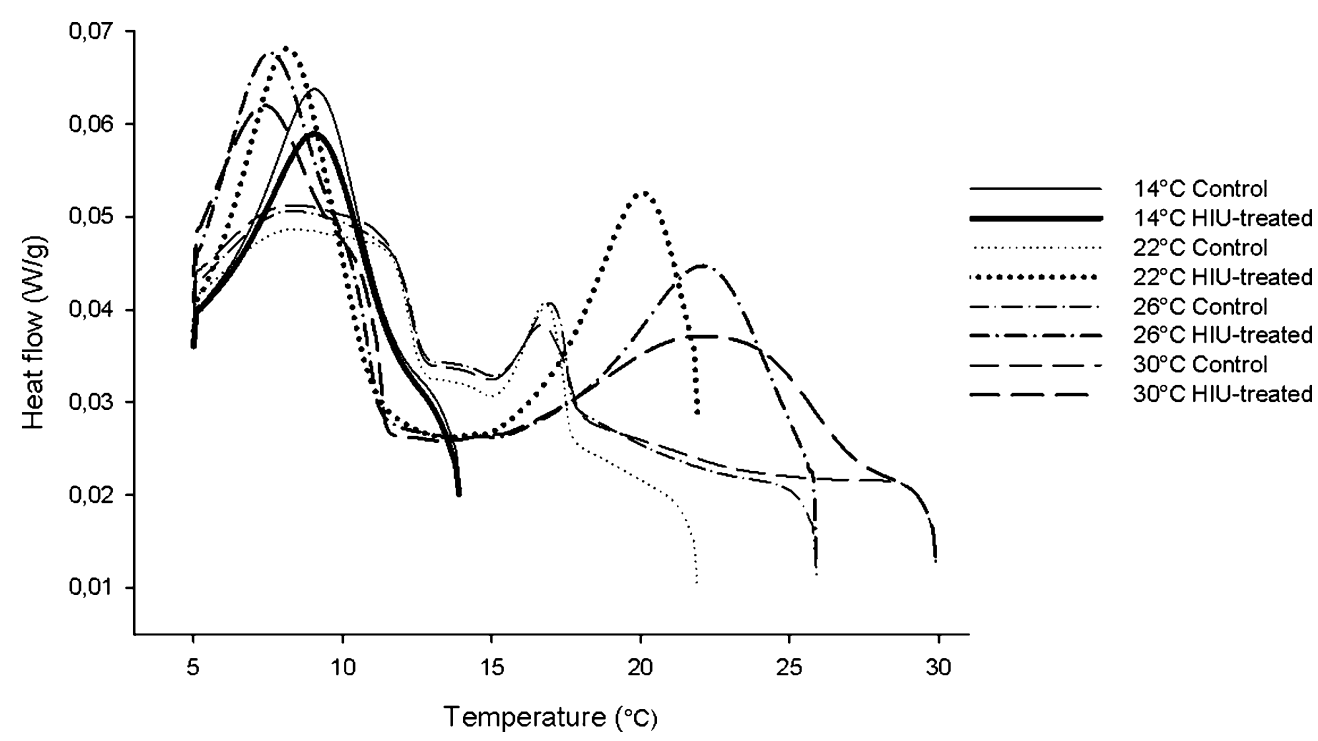

Figure 1. Differential scanning calorimetry. Crystallization curves of HIU-treated and untreated AMF cooled $0.5{ }^{\circ} \mathrm{C} / \mathrm{min}$ from the given $\mathrm{HIU}$ application temperature to $5{ }^{\circ} \mathrm{C} .14{ }^{\circ} \mathrm{C}, 22{ }^{\circ} \mathrm{C}, 26^{\circ} \mathrm{C}$, and $30^{\circ} \mathrm{C}$ indicate $\mathrm{HIU}$ treatment temperatures.
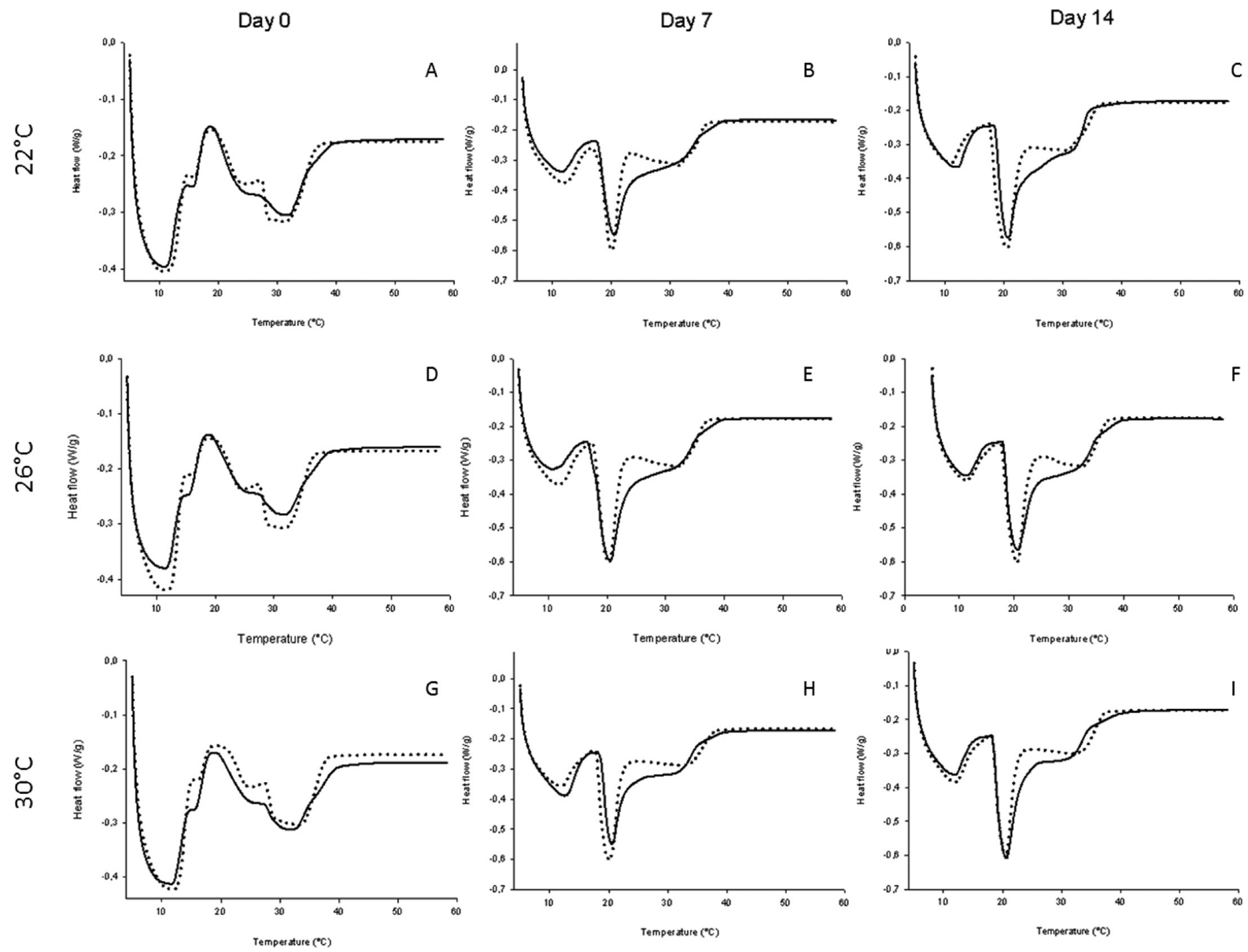

Figure 2. Melting curves of HIU-treated and untreated AMF melted immediately after cooling to $5{ }^{\circ} \mathrm{C}(\mathrm{A}, \mathrm{D}, \mathrm{G})$, after 7 (B, E, H) or 14 days $(\mathrm{C}, \mathrm{F}$, I) of storage at $5{ }^{\circ} \mathrm{C}$. Heating rate: $5{ }^{\circ} \mathrm{C} / \mathrm{min} .22{ }^{\circ} \mathrm{C}, 26^{\circ} \mathrm{C}$, and $30^{\circ} \mathrm{C}$ indicate HIU treatment temperatures. Dotted lines are HIU-treated AMF; solid lines are control.

scanning calorimetry. The AMF was rapidly cooled from $65^{\circ} \mathrm{C}$ to either $14,22,26$, or $30^{\circ} \mathrm{C}$ and treated with HIU before slowly cooling to $5{ }^{\circ} \mathrm{C}$. When HIU was applied at temperatures of $22{ }^{\circ} \mathrm{C}$ or higher, the thermographs of AMF showed two exothermic peaks (Figure 1). The onset and shape of the peaks were treatment-dependent. The control samples showed a narrow peak at $16.8{ }^{\circ} \mathrm{C}$ and a broader one at $8.3{ }^{\circ} \mathrm{C}$, representing the high (HMF) and low melting fractions (LMF), respectively. The onset of crystallization of HMF of HIU-treated AMF was 21.9, 25.6, and $27{ }^{\circ} \mathrm{C}$ when HIU was 
A

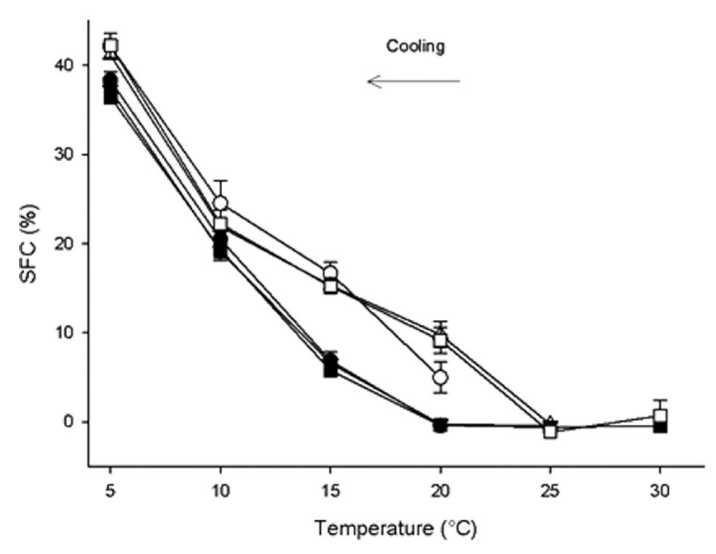

B

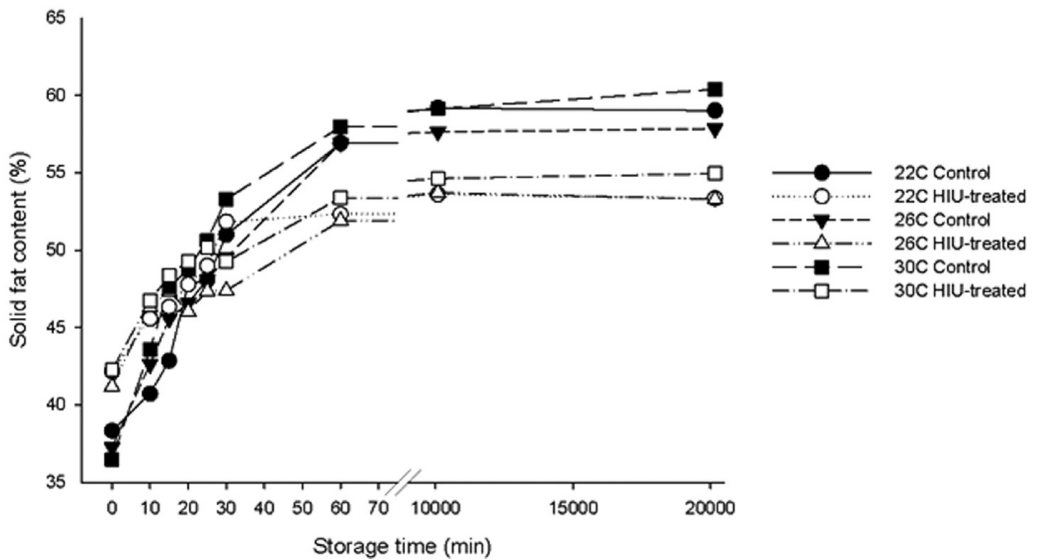

Figure 3. Solid fat content of HIU-treated (empty symbols) and untreated (filled symbols) AMF as a function of temperature during cooling (A) or storage time at $5{ }^{\circ} \mathrm{C}$. (B). $22{ }^{\circ} \mathrm{C}, 26^{\circ} \mathrm{C}$, and $30^{\circ} \mathrm{C}$ indicate HIU treatment temperatures. Error bars indicate standard deviations.

applied at 22,26 , and $30{ }^{\circ} \mathrm{C}$, respectively. Crystallization onset in the control samples was at $17.6{ }^{\circ} \mathrm{C}$, thus HIU mediated a shift in onset temperature toward significantly higher temperatures.

Acceleration of crystallization is of great significance to the food industry as this could shorten the processing time and hence reduce processing costs. The differences in the crystallization onsets for the HIU-treated samples appear to be related to the degree of supercooling of the system. Upon HIU treatment, the LMF started to crystallize at a lower temperature and in a narrower peak, indicating more homogeneity of the crystallizing TAGs. HIU treatment appears to greatly affect the HMF of AMF, and to a lesser extent the LMF (Figure 1).

Earlier studies have shown that HIU treatments at $22{ }^{\circ} \mathrm{C}$ delay crystallization onset, ${ }^{15}$ whereas our results indicate that crystallization was initiated immediately after HIU-treatment at $22{ }^{\circ} \mathrm{C}$. It is, however, important to note, that our study focuses on non-isothermal crystallization, whereas isothermal conditions are applied in earlier studies, and nucleation is promoted as the temperature decreases and thus supercooling increases. Additionally, sonication parameters applied in the two studies are different; in this study an energy density of 17.5 $\mathrm{J} / \mathrm{mL}$ was applied using an ultrasound processor operating at 24 $\mathrm{kHz}$, whereas Martini et al. ${ }^{15}$ apply $20 \mathrm{kHz}$.

At a high supercooling level, that is, $14{ }^{\circ} \mathrm{C}$, no effect of HIU treatment on the crystallization behavior was observed. One explanation to this could be that HIU affects the nucleation phase, and at $14{ }^{\circ} \mathrm{C}$, crystallization is already ongoing at the time of HIU treatment. Additionally, the higher viscosity of AMF at this temperature could impair cavitation and thereby heat and mass transfer, as the high viscosity may hinder bubble implosion or even formation of bubbles.

The melting profile is an important determinant for the sensory properties of a lipid product, as it is related to palatability and mouthfeel. In particular, steeper melting peaks are associated with faster melting in the mouth, which often is a desired property in lipid-containing products. ${ }^{17}$ The melting profile of a lipid system is influenced by, for example, the amount of crystalline material, the size of the crystals, and TAG composition.

HIU treatment resulted in small alterations of the melting profiles immediately after cooling, where peaks appeared sharper and more defined (Figure 2A,D,G). After storage, three peaks were observed at 11,20 , and $30^{\circ} \mathrm{C}$. The differences between HIU-treated and control AMF were more pronounced, and the HIU-treated AMF gave rise to more defined and narrow peaks at 20 and $30{ }^{\circ} \mathrm{C}$ (Figure 2B,E,H). The difference between HIU-treated and control AMF was sustained during further storage (Figure 2C,F,I).

The major melting peak at $20{ }^{\circ} \mathrm{C}$ became steeper and sharper, which could be explained by smaller crystals. This will be discussed in a later section. Additionally, it is possible that the similarity of the crystallized TAGs contributes to this sharper profile observed in the HIU-treated samples. The broader melting peak for the control indicates a greater content of mixed crystals and/or a different packing of the TAGs.

Development of Solid Fat. The crystallization process was also followed by SFC measurements. The initial formation of solid fat was detected at higher temperatures in the HIUtreated samples compared to the control samples (Figure 3A). The results indicate that crystallization was initiated at higher temperatures, which correlates well with the results obtained by DSC. The slopes of the SFC curves were less steep in the HIUtreated samples, regardless of HIU temperatures, compared to the control. This indicates that crystallization may be initiated at higher temperatures, when applying HIU; however, the rate of solid fat development appears slightly lower than for the control. A possible explanation hereof could be that HIU affects specific TAGs, and the following incorporation of these TAGs to the growing crystal lattice is more time-consuming. From 10 to $5{ }^{\circ} \mathrm{C}$, the rates appear to be similar, independent of treatment, possibly because it is the less-affected LMF that crystallizes at these temperatures; however, SFC of the HIUtreated samples were approximately 5\% higher. SFC determinations were performed under isothermal conditions by Suzuki et al., ${ }^{14}$ and they reported only minor differences between HIUtreated and control AMF; thus the type of crystallization (isothermal vs. non-isothermal) appears to greatly influence the effects of HIU on development of solid fat.

The crystallization process and organization of the fat crystal network continued after $5{ }^{\circ} \mathrm{C}$ was reached (Figure 3B). Initially, SFC in the HIU-treated samples was higher, but after approximately $20 \mathrm{~min}$ at $5{ }^{\circ} \mathrm{C}$, the curves intersected, and SFC in control samples became higher than in HIU-treated samples from this time onward. After $1 \mathrm{~h}$, a plateau was reached, and 


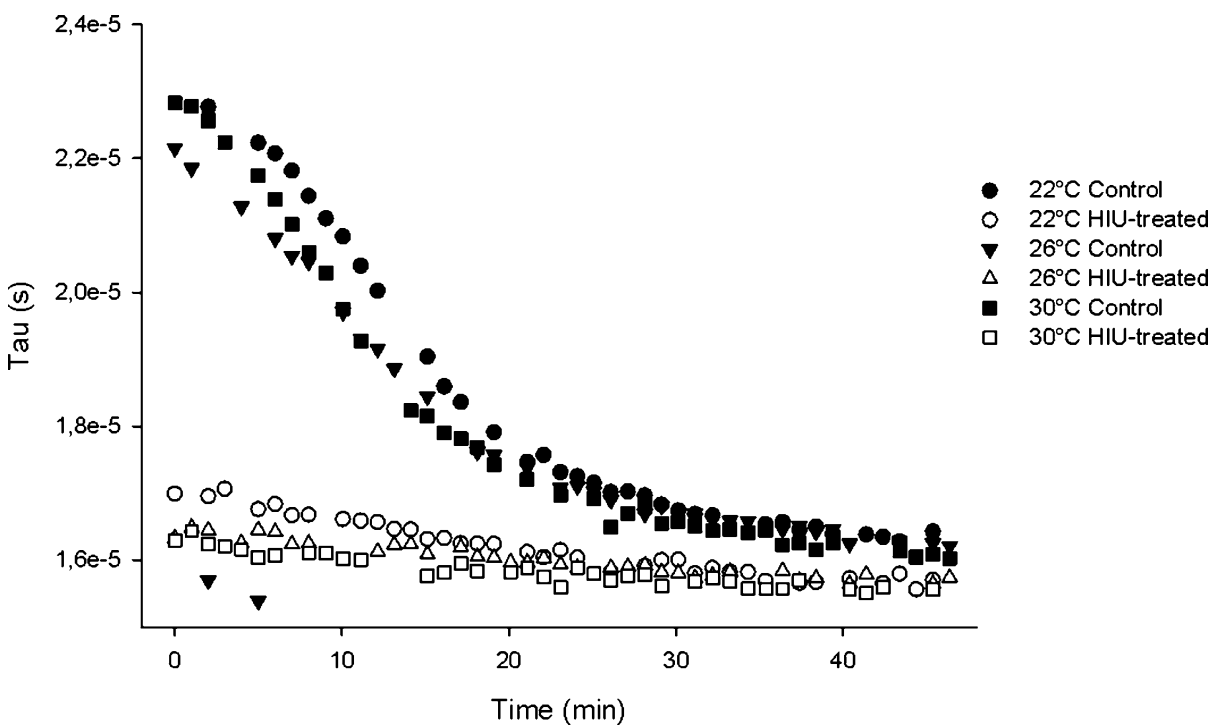

Figure 4. Crystal polymorphic behavior of HIU-treated and untreated AMF after storage at $5{ }^{\circ} \mathrm{C} .22{ }^{\circ} \mathrm{C}, 26{ }^{\circ} \mathrm{C}$, and $30{ }^{\circ} \mathrm{C}$ indicate $\mathrm{HIU}$ treatment temperatures. Empty symbols: HIU-treated AMF; filled symbols: control AMF.

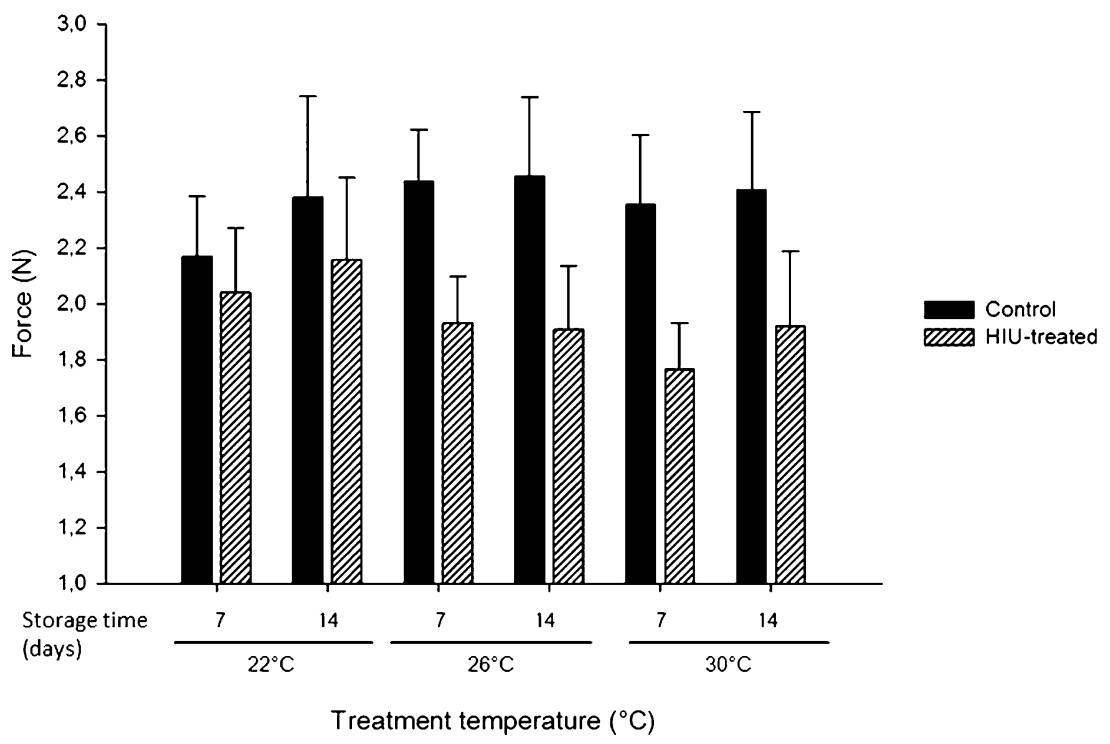

Figure 5. Hardness of HIU-treated and control AMF after storage for 7 or 14 days at $5{ }^{\circ} \mathrm{C} .22{ }^{\circ} \mathrm{C}, 26{ }^{\circ} \mathrm{C}$, and $30{ }^{\circ} \mathrm{C}$ indicate $\mathrm{HIU}$ treatment temperatures.

only small increases in SFC were observed afterward. This pattern was observed for both the HIU-treated and control AMF; however, HIU treatments resulted in 5\% less solid fat after 14 days of storage.

These results demonstrate that HIU-treatment affect the crystallization kinetics of milk fat, that is, polymorphic transition and/or causing other types of mixed crystal and thereby altering the fractional crystallization.

Differences in crystallization kinetics observed by DSC and pNMR could be attributed to alterations in the TAG compositions of the crystallized and noncrystallized fractions of AMF. It was not possible to detect significant changes in TAG composition of these fractions by GC analysis (data not shown), and thus it is more likely that the observed differences are caused by altered packing of the TAGs.

Polymorphic Behavior. The observed shape of the SFC curves (Figure 4) could be related to changes in crystal polymorphism; therefore polymorphic behavior was evaluated during the first $48 \mathrm{~min}$ of storage. Polymorphic transition of crystals can be detected by pNMR by measuring the solid-state decay constant $\left(\tau\right.$, seconds). ${ }^{18}$ As the crystal transforms from the less dense $\alpha$ crystal packing to the denser $\beta^{\prime}$ crystal, the change in the carbon packing results in a decrease in $\tau$ value, and thus the $\tau$ value relates to the polymorphic composition of a crystalline material.

Small $\tau$ values were obtained for the HIU-treated AMF, indicating that the crystals were primarily $\beta^{\prime}$, and this was observed irrespective of HIU application temperature (Figure 4). On the contrary, control AMF displayed high $\tau$ values, which decreased as a function of storage time, indicating transformation from $\alpha$ to $\beta^{\prime}$ in these samples. Our results indicate that HIU treatment promotes formation of the $\beta^{\prime}$ crystal polymorph. From these experiments, it is, however, not possible to determine whether HIU causes AMF to crystallize directly into the $\beta^{\prime}$ form or it accelerates the process so that transformation takes place earlier in the crystallization process. 

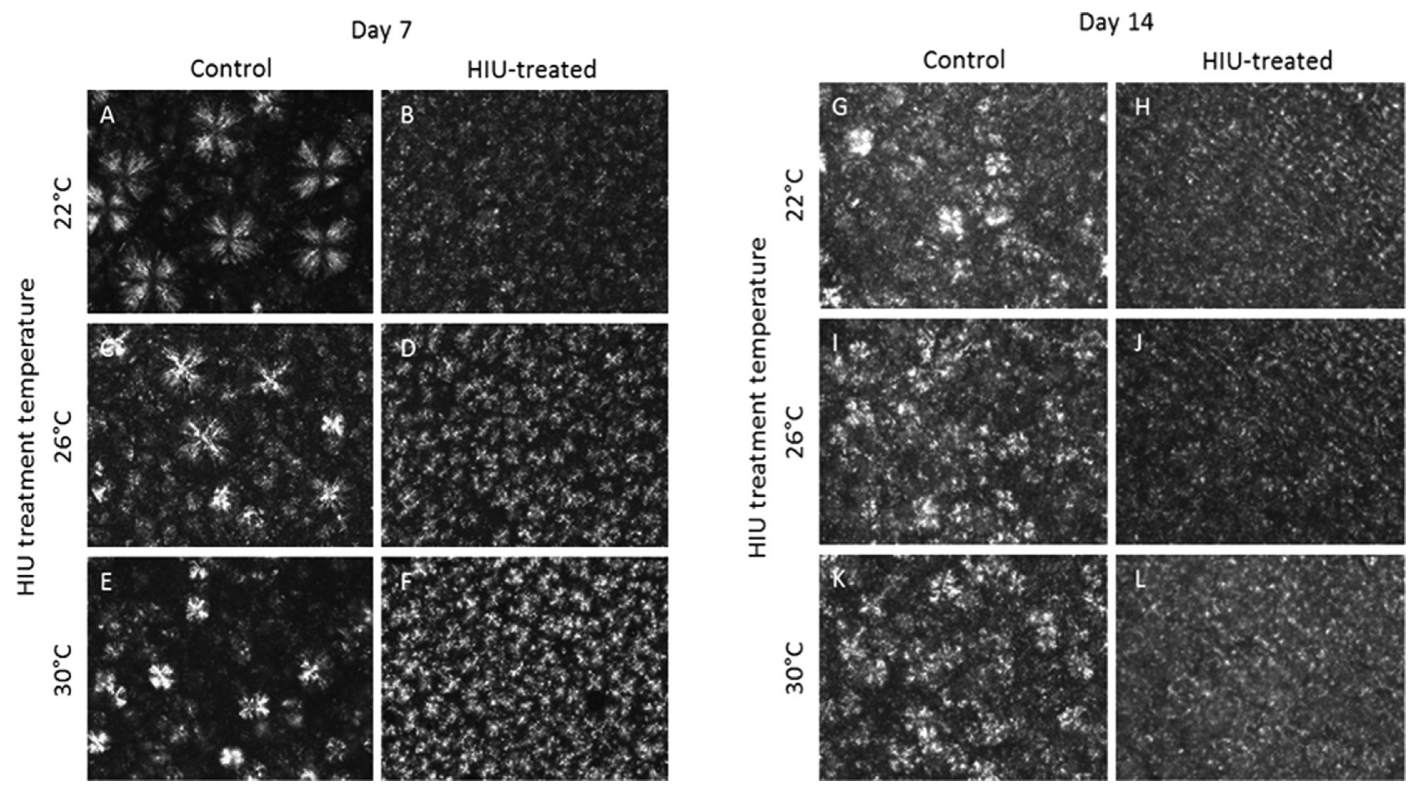

Figure 6. Microstructure of HIU-treated and untreated AMF visualized using polarized light microscope after storage for (left) 7 or (right) 14 days. $22{ }^{\circ} \mathrm{C}, 26{ }^{\circ} \mathrm{C}$, and $30{ }^{\circ} \mathrm{C}$ indicate $\mathrm{HIU}$ treatment temperatures.

The applied method for determining crystal polymorphism has the disadvantage of only being capable of distinguishing between $\alpha$, and $\beta$ and $\beta^{\prime}$, but not between $\beta$ and $\beta^{\prime}$. However, as AMF to a great extent tends to crystallize in the $\beta^{\prime}$ polymorph, we assume that the $\beta / \beta^{\prime}$ signal corresponds to the $\beta^{\prime}$ polymorphic form. ${ }^{19}$

Texture and Crystal Morphology. The amount of crystalline material in a fat system influences the texture and hardness of a fat crystal network. Thus the decrease in SFC led us to expect a softer material which the texture analysis also revealed for all HIU treatment temperatures (Figure 5). At day 7 , there was a significant effect on hardness as a function of HIU treatment temperature when HIU was applied at 26 and $30{ }^{\circ} \mathrm{C}$; higher treatment temperatures were correlated with softer materials. After 14 days of storage, AMF treated with HIU at 26 and $30{ }^{\circ} \mathrm{C}$ was similar in regard to softness, and these samples were the softest. AMF treated with HIU at $22^{\circ} \mathrm{C}$ was intermediate, and the control was the hardest. These results are different compared to an earlier study which reports a harder material after HIU treatment. ${ }^{15}$ However that study was focused on isothermal crystallization using different ultrasonication parameters. Our results further emphasize that the degree of supercooling is influential, and high supercooling diminishes the effect of HIU treatment. Furthermore, the results indicate that by changing HIU treatment temperature, applied energy density, and frequency it is possible to manipulate crystallization in order to obtain a desired hardness.

Another factor that affects the hardness of a lipid system is the crystal size, where smaller crystals typically are associated with harder or stiffer material. ${ }^{20,21}$ The HIU treatment clearly reduced crystal size, and more uniform crystal sizes were obtained (Figure 6). Furthermore, the number of crystals increased, indicating that HIU promoted nucleation. Reduced crystal sizes as a result of HIU treatments are also reported in previous studies. ${ }^{14,15}$ After 7 days of storage, large spherulites were observed in the control samples. In contrast, HIU-treated AMF consisted of many, very small crystals with dense spherulite structures and a denser network (Figure 6). This trend was observed irrespective of HIU treatment temperature.
After 14 days, more crystalline material was formed, and the fat crystal network was denser for all samples (Figure 6). However, the crystal sizes were still clearly smaller in the HIU-treated samples.

Earlier studies on ultrasonication report that crystallization occurs in the immediate vicinity of the cavitation bubble. ${ }^{9,12}$ The mechanisms responsible for the faster crystallization, reduced crystal sizes, and increased number of crystals obtained by HIU could be ascribed to (i) micro bubbles formed by cavitation act as impurities that promote heterogeneous nucleation or (ii) the induction of turbulence, causing better heat and mass transfer, leading to a reduction in the supercooling needed to initiate nucleation. Additionally, the shear forces, turbulence, and acoustic streaming associated with the cavitation zone mediates fragmentation of already existing crystals, thereby promoting secondary nucleation. The latter is especially relevant at higher supercooling levels, where nucleation is already occurring, when HIU is applied. However, the collapse of microbubbles should theoretically release heat and thereby melt the nuclei and delay crystallization process.

The effect of smaller crystal clusters on hardness was overruled by the lower SFC; however, brittleness of a material is another important macroscopic and sensory property to consider when producing food lipid products. Brittleness affects spreadability and mouthfeel. We assessed the brittleness by penetration tests using a cone, where the irregular peaks on the curve indicate local fracture points of the structure, and therefore the number and size of peaks can act as an indicator of brittleness.

HIU treatment resulted in smoother lines with fewer or no irregularities compared to the control, indicating that the HIUtreated AMF was less brittle (Figure 7). The effect was especially pronounced when HIU was applied at $30{ }^{\circ} \mathrm{C}$, where the curves were nearly smooth lines (Figure 7C). This was observed after 7 days of storage, and the effect was sustained after 14 days. HIU applied to AMF at $26{ }^{\circ} \mathrm{C}$ resulted in a lower level of brittleness after 7 days of storage, and it became less brittle after further storage, compared to control AMF (Figure 7B). At a higher supercooling, that is, $22{ }^{\circ} \mathrm{C}$, the effect was 


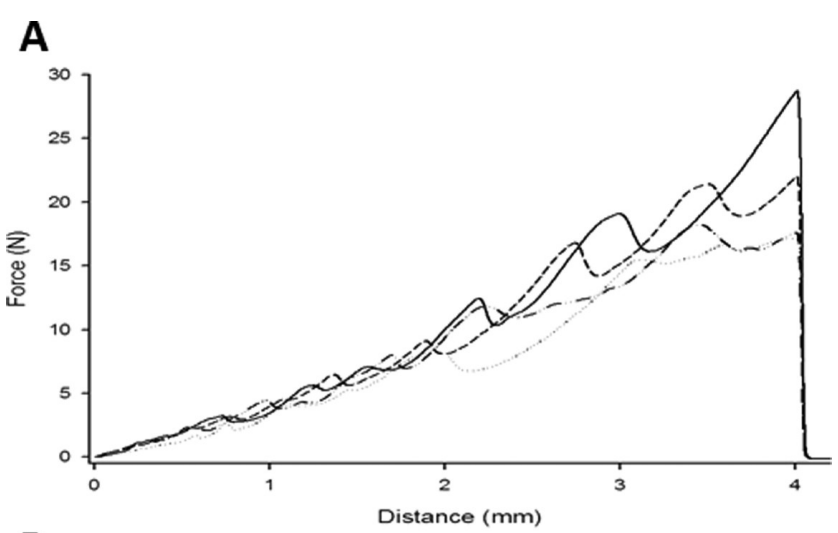

B
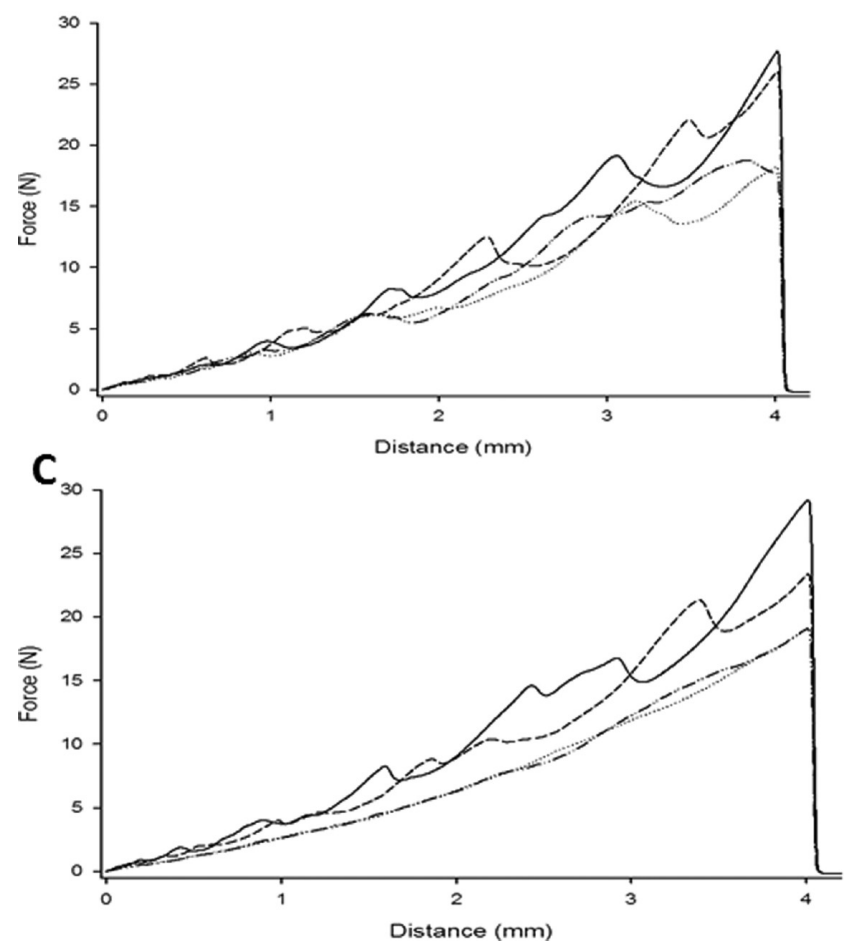

Figure 7. Brittleness of HIU-treated and untreated AMF assessed by cone penetration after storage for 7 or 14 days at $5{ }^{\circ} \mathrm{C}$. (A) HIU treatment at $22{ }^{\circ} \mathrm{C}$. (B) HIU treatment at $26^{\circ} \mathrm{C}$. (C) HIU treatment at $30{ }^{\circ} \mathrm{C}$. Full lines: control day 7; dotted lines: HIU-treated day 7 ; dashed lines: control day 14; dash-dotted lines: HIU-treated day 14.

minimal after 7 days of storage, and the curves were slightly smoother after longer storage time (Figure 7A). The degree of supercooling appears to also affect the level of brittleness, as a higher HIU treatment temperature was observed to be related to increased brittleness. The small crystals of uniform size and the low SFC correlate well with the results obtained when HIU was applied at $30^{\circ} \mathrm{C}$, but to lesser extents when HIU treatment temperatures decreased. These differences may be mediated by changes in the bonds formed during crystallization. When applying HIU at a low level of supercooling, that is, $30^{\circ} \mathrm{C}$, nucleation has not yet begun, and HIU has a greater impact on the primary nucleation where perhaps more bonds are formed, creating a more flexible network consisting of many small crystals. We suggest that HIU exerts its greatest effects on the nucleation phase of crystallization, and as more nucleation has already occurred at the time of HIU treatment when applied at $26^{\circ} \mathrm{C}$ or even more at $22{ }^{\circ} \mathrm{C}$, the extent of effects caused by the
HIU treatment is reduced, and this manifests itself in a reduced effect on brittleness.

Our results indicate that HIU treatment accelerates the whole crystallization process causing a shift toward higher temperatures. The factors that appear to play the most important roles are type of crystallization and degree of supercooling. We have shown that HIU treatment affects the development of the fat crystal network on the nanoscale level, the microscopic level, and consequently on the macroscopic level. We have shown that the effects can be detected shortly after HIU treatment, and they are sustained or even further evolved during storage. This study contributes to a better understanding of the effects and mechanisms of HIU on lipid systems, and it sheds light on the long-term effects which are very important in order to implement this method as an additional processing tool in the food industry.

\section{AUTHOR INFORMATION}

\section{Corresponding Author}

*E-mail: Lars.Wiking@agrsci.dk. Phone: +45 87157805.

\section{Notes}

The authors declare no competing financial interest.

\section{ACKNOWLEDGMENTS}

The authors wish to thank the Danish Dairy Research Foundation, Arla Foods, Future Food Innovation and the inSPIRe Food Platform for financial support of this project.

\section{REFERENCES}

(1) Mert, B.; Campanella, O. H. J. Food. Eng. 2007, 79, 546-552.

(2) Ashokkumar, M. Ultrason. Chem. 2011, 18, 864-872.

(3) Patist, A.; Bates, D. Innovative Food Sci. Emerging Technol. 2008, $9,147-154$.

(4) Jayasooriya, S. D.; Torley, P. J.; D'arcy, B. R.; Bhandari, B. R. Meat Sci. 2007, 75, 628-639.

(5) Sanchez, E. S.; Simal, S.; Femenia, A.; Llull, P.; Rosello, C. Eur. Food Res. Technol. 2001, 212, 147-152.

(6) Riener, J.; Noci, F.; Cronin, D. A.; Morgan, D. J.; Lyng, J. G. Food Chem. 2009, 114, 905-911.

(7) Higaki, K.; Ueno, S.; Koyano, T.; Sato, K. J. Am. Oil Chem. Soc. 2001, 78, 513-518.

(8) Chow, R.; Blindt, R.; Chivers, R.; Povey, M. Ultrasonics 2003, 41, 595-604.

(9) Chow, R.; Blindt, R.; Chivers, R.; Povey, M. Ultrasonics 2005, 43, 227-230.

(10) Patel, S. R; Murthy, Z. V. P. Cryst. Res. Technol. 2009, 44, 889896.

(11) Lauterborn, W.; Kurz, T.; Mettin, R.; Koch, P.; Kroninger, D.; Schanz, D. Arch. Acoust. 2008, 33, 609-617.

(12) Martini, S.; Tejeda-Pichardo, R.; Ye, Y.; Padilla, S. G.; Shen, F. K.; Doyle, T. J. Am. Oil Chem. Soc. 2012, 89, 1921-1928.

(13) Ueno, S.; Ristic, R. I.; Higaki, K.; Sato, K. J. Phys. Chem. B 2003, $107,4927-4935$.

(14) Suzuki, A. H.; Lee, J.; Padilla, S. G.; Martini, S. J. Food Sci. 2010, 75, E208-E214.

(15) Martini, S.; Suzuki, A. H.; Hartel, R. W. J. Am. Oil Chem. Soc. 2008, 85, 621-628.

(16) Marangoni, A. G.; Lencki, R. W. J. Agric. Food Chem. 1998, 46, 3879-3884.

(17) Bessler, T. R; Orthoefer, F. T. J. Am. Oil Chem. Soc. 1983, 60, $1765-1768$

(18) Janssen, P. W. M.; MacGibbon, A. K. H. J. Am. Oil Chem. Soc. 2007, 84, 871-875.

(19) Timms, R. E. Aust. J. Dairy Technol. 1980, 35, 47-53.

(20) Wiking, L.; de Graef, V.; Rasmussen, M.; Dewettinck, K. Int. Dairy J. 2009, 19, 424-430. 
(21) Vereecken, J.; Foubert, I.; Smith, K. W.; Dewettinck, K. J. Agric. Food Chem. 2007, 55, 7793-7801. 